\title{
Thought on Supply Chain Management of Chain Stores
}

\author{
Chao Liu \\ Huaian Vocational Collage of Information Technology, Huaian Jiangsu, 22300, China
}

Keywords: Chain, Operating enterprise, Supply chain, Management.

\begin{abstract}
Chain enterprises face some bottlenecks in the development of our country. Due to the scarcity of scientific management ideas, unscientific management methods and management tools have become the limiting factors. In the development of modern information network, providing management strategies for its development can promote the realization of the meaning of work. In this paper, I give some thoughts about supply chain management of chain stores.
\end{abstract}

\section{Introduction}

Chain stores are the main forms of the development of the retail industry. Despite their short history of development, they can also provide convenience for customers, ensure better quality and products and are welcomed by consumers. In China's commercial competition and development, achieving chain operations not only establishes new distribution for business development to provide a reasonable mode of operation, but also implements advanced supply chain management mode in the development of modern e-commerce, to ensure that stable survival has been achieved in the development of a highly competitive market.

\section{The Content of Supply Chain Management}

Based on the final customer needs, supply chain management is to provide products, services and business-related information resources, to promote the implementation of management using software products with INTER-NET technology, and to optimize the entire platform in the whole channel and business process. Supply chain management is to optimize the entire work during the actual implementation of supply chain management and to reduce costs so as to promote the stable implementation of all work. At the same time, the internal and external resources of enterprises are to be coordinated in supply chain management to meet the development needs of consumers. In the overall work, all the components are dynamic and give full play to their changes according to the development of the market demand. In a certain level of customer service, in order to meet sufficient conditions and reduce the cost of the whole supply chain system, it is guaranteed that the overall work put suppliers, manufacturers, distributors and other distribution centers together to promote the conjoining development of product manufacturing, distribution and sales. Supply chain management is also a kind of integrated thinking of enterprises. The realization of effective development of management asks for the optimization of the enterprise strategy and technology, the promotion of the efficiency of work operations, and the quality of the products. Therefore, the positive development of the whole process will be promoted.

\section{The Significance of Supply Chain Management}

In supply chain management, the overall efficiency and value creation have relations with the value that the final customer obtains. To achieve supply chain management, the most essential purpose of the work is to coordinate and optimize all aspects of the supply chain, and to promote the realization of its development value and ensure higher efficiency. The optimization of business processes and access to strategic work can achieve greater efficiency among businesses and enhance the level of business processes in supply chain management. At the same time, to realize supply chain 
management, we must regard the channel as the core and infiltrate it within a certain range so as to facilitate the positive development of the enterprise and the realization of the business process. The realization of supply chain management can also obtain the final customer demand information, according to the actual development needs of enterprises, match it with the product capabilities and business partners, etc., to determine supply and demand plans for themselves, to set appropriate plans for themselves and their business partners, etc., to provide an effective development process for supply and demand plans to make sure to meet the actual development needs of the final customer, and also to achieve effective application[1].

At present, with the gradually showing trend of market competition, enterprises have formed the competition and development among the networks. The network optimization features of enterprises are the true meaning of chain enterprises' development in the supply chain management. Therefore, it's very important for chain enterprises to achieve supply chain management, not only to promote the effective supply of business needs, but also to enhance the overall ability to reflect and ensure the full use of resources. The current analysis shows that once chain enterprises achieve supply chain management, the loss reduction efficiency will be $40 \%-50 \%$, with the dropping inventory by $10 \%$ $-15 \%$, which shows more effective cost savings. In order to promote the implementation of supply chain management in the development of chain enterprises, we must reorganize business processes and promote the improvement of modern management level based on the application of advanced technologies and scientific management methods.

\section{Supply Chain Management Countermeasures of Chain Stores}

\subsection{To achieve internal integration}

In the development of chain stores, the content of supply chain management is integrated internally. In the work, we mainly integrate the procurement of raw materials, parts and components, transportation work and distribution in the enterprise to ensure that we meet the development needs of our customers. In the integration process, the conjoining development of all aspects can promote supply chain management. Throughout the supply chain, it is delivered to customers and involved in supply, production, distribution and sales to promote the growth of companies and businesses. At the same time, the implementation of supply chain management is to combine suppliers and buyers to ensure that they fully reflect the development needs of the market. For the purpose of supply chain management, analyze its time, quantity, quality and correct state according to the products a customer needs, so as to improve customer satisfaction and reduce the overall cost of production in business operations.

The realization of supply chain management, based on the supply chain distribution center, upstream suppliers and downstream suppliers, optimizes and integrates their chain work, to promote the development of the product value, and supply it to consumers. This will not only achieve internal logistics management of chain stores, reduce business inventories and ensure the optimization and development of services, but also connect chain businesses with suppliers, so as to optimize and allocate social resources and to guarantee the effective implementation of all work. In actual work, we must do a good job in several aspects.

First, change the ideas and concepts of retail business. In order to obtain higher efficiency, chain enterprises need to change the overall supply chain, focus on corporate profits and grasp supply chain management in all aspects. However, we must also make clear the actual profits of enterprises and focus on the analysis of partner channels. Retailers cannot take channel partners as competitors to ensure a favorable position among different supply chains [2].

Second, optimize business processes. The main goals in supply chain management are to promote the transparency of management, allocate various resources in the supply chain and promote the gain of profits. For the chain, its transparency can analyze the sales in the supply chain industry at any time to ensure timely replenishment. The transparent development of enterprise internal information will promote the normative business processes, provide higher conditions for the prediction work, and provide effective technology and improve the implementation of the strategy for supply chain 
management.

Third, cultivate supply chain personnel. In the process of actual development, because of the special organization form, chain enterprises can promote the integrated development of various circulation organizations and forms, and make them conform to the operating characteristics and mode of operation. At the same time, according to certain requirements of development, the managers and ordinary staff can get some knowledge in chain enterprises. Therefore, it is very necessary to intensify efforts to train qualified personnel in chain stores[3].

\subsection{To achieve external coordination}

First, strengthen the relations with strategic partners. A good supply chain management is mainly the optimization of the raw materials, distributors, distributors, retailers and customers, etc. The implementation of supply chain management should not only infiltrate more ideas, but also need to integrate the external and users within the supply chain, maintain the relationship between users and partners, and promote the integrated development of supply chain management. In supply chain management, we regard the partner as the key to maintain the relationship between enterprises and users, suppliers and service providers and complete the product design, production and transportation so as to promote the stable operation of the whole supply chain management.

Second, achieve the development of shared information resources. The sharing of information can provide effective conditions for supply chain management of chain stores. Therefore, the chain management companies should actively guide the work, develop the information of enterprises, achieve electronic supply chain management in accordance with corporate resources and implementation plan, and promote the realization of the system platform, which not only provides convenience for the internal development of enterprises, but also realizes information sharing in the entire supply chain development.

Third, be honest and trustworthy. The implementation of supply chain management is an identical chain structure. Take the core enterprises as the basic conditions for the composition of the users in the suppliers, promote the good development in every node of enterprises and maintain the relationship between business demand and supply. Each node of the enterprise should abide by the principle of honesty and trustworthiness, reduce the crisis of trust and the transaction cost between the cooperative enterprises, and facilitate the long-term development and stable implementation of the supply chain.

\subsection{To improve the management level}

First, set up logistics and distribution center infrastructure. In the whole chain system, the distribution center is the center of the logistics operation of the chain system, which delivers the goods during the period of receiving the supply chain goods and promotes the realization of the entire logistics process. For large quantities of goods, each purchase of goods and business can be converted during the purchase. In the work, the distribution center is in charge of verification, storage, etc., for all categories, large quantities of goods and meanwhile of classification, organization and storage of commodities. It promotes the optimization and completion of all kinds of work when the goods are received, and processes the information in processing and distribution to ensure the optimization and completion of all businesses. Distribution center needs more scientific management and its application to the chain operations. According to the actual development of chain enterprises, the potential for development should be fully explored. At present, many chain stores in our country have a delivery rate of $30 \%-60 \%$ and a unified delivery rate of no less than $80 \%$. The construction of distribution centers will provide constraints for China's development of chain enterprises., The continuous development of the scale of chain enterprises in recent years has realized the role of distribution center development, handled the chain in the work of the distribution system, promoted access to economic benefits and ensured management and operational efficiency to make sure to meet the overall development needs[4].

Second, adopt the third-party logistics. In order that enterprises get more benefits and efficiency and enhance the overall core strength of enterprises, we must lower the working cost and realize the realization of logistics strategy based on certain requirements during the innovation of enterprise 
logistics, so as to get more benefits in the society. The realization of the third-party logistics enterprises can integrate the supply chain in their work, increase their efforts to enhance the competitiveness of enterprises, enhance the efficiency of labor production and ensure the improvement in all aspects [5].

\subsection{To achieve information construction}

Promote the development of enterprise information in supply chain management, which is mainly achieved through the application of modern information technology, such as bar code, point-of-sale system and data exchange systems, etc. With advanced management ideas, its application to the information system provides rich forms of management for the production and management of enterprises, meets and real-time grasps the actual development needs of customers, so as not only to more accurately implement the inventory, slow-moving, production, procurement and other work, but also to combine the supply chain cooperation system and business management system to adapt to many development needs of the market and customers and to offer products high quality service.

In order to be able to adapt to the mode of socialized production, organize their work, and enhance the overall efficiency of the project, in the process of building a distribution center, chain stores can meet the needs of commercial production. Distribution centers can be used as the main form of circulation to enhance the retailer's competitive position and get access to good economic benefits. During the construction of the distribution center, based on the establishment of distribution, the company carried out the purchase, sales and operation of the chain management work and maintained the overall operation standards so as not only to reduce the circulation costs but also to promote the realization of the service targets. The turnover rate of goods should be reduced, and the business performance should be changed to ensure the development of greater potential according to the advantages of chain stores. It is also necessary to open up new marketing channels in the chain operations and to set up a new mode of operation logistics in the establishment. Based on the construction of distribution center, it will be regarded as the core of system logistics operation to ensure the stable implementation of the whole logistics work process so as to promote the realization of various industries; also, commodities will be classified and stored, when receiving the goods information; the information of goods will be distributed to ensure its transmission; at the same time, the circulating information and business should be processed and handled; in the management of distribution centers, it is important to promote its scientific nature, to recognize each of the problems, to analyze the real development of chain enterprises in more details and to play a greater role in mining enterprise development potential. Therefore, various aspects of work are applied in the chain system and enterprises are effective as a basis to avoid inconsistence with the substantive standards of the chain, which not only can gurantee the overall development benefits of our chain enterprises, but also can meet the development requirements in the new era.

\section{Conclusions}

Based on the above analysis and research, it can be found that supply chain management for chain stores can provide guarantee to the maximum extent of development and ensure the steady commercial progress and development. In many chain stores, the mode of management work is more important and needs to be fundamentally infiltrated. Based on the need of informatization, the management mode should be integrated with each other so as to achieve higher efficiency.

\section{References}

[1] He Xiaolan. Analysis of the Operation and Management of Chain Supermarkets in Multi-format Environment - A Case Study of Beijing Chain Store Chain Co., Ltd, Capital University of Economics and Business, 2015.

[2] Huang Rong. Analysis of Purchasing Management of Pharmaceutical Retail Chain in Guangxi Based on Supply Chain Management Theory, Technology and Business Enterprise, 2015(7):8-10, 13. 
[3] Liu Li. How to Implement Supplier Evaluation Management in Chain Stores Management, Chinese and Foreign Corporate Culture (Late Nov. Edition) 2014(11):28-29.

[4] Zhao Chen. Discussion on the Management and Development Model of Chain Retail Enterprises in the Supply Chain Perspective, Business Economics Research, 2017(4):41-42.

[5] Jack Liu. Franchise chain operations in the Internet age, Managers, 2012(11):91-92. 